\title{
Project-Based Learning in Personal-Oriented Educational Paradigm
}

\author{
Anna Vladimirovna Shutaleva \\ Associate Professor, Candidate of Philosophy, \\ Ural Federal University named after the first President \\ of Russia B.N. Yeltsin, \\ Ural State Law University \\ Ekaterinburg, Russia, \\ e-mail: a.v.shutaleva@urfu.ru
}

\author{
Yulia Vladimirovna Tsiplakova \\ Associate Professor, Candidate of Philosophy, \\ Ural Federal University named after the first President \\ of Russia B.N. Yeltsin, \\ Ural State Law University \\ Ekaterinburg, Russia, \\ e-mail: julia.tsiplakova@urfu.ru
}

\author{
Evgenia Anatoljevna Putilova \\ Associate Professor, Candidate of Philosophy, \\ Ural Federal University named after the first President of Russia B.N. Yeltsin, Nizhny Tagil Technological Institute \\ (branch) UrFU \\ Nizhny Tagil, Russia, \\ e-mail: eazhiltsova@mail.ru
}

\begin{abstract}
The modern education system forms on principles such as the integration of knowledge, humanism, dialogism, and culture of dignity. The relevance of the study of a personalityoriented education system development is due to the requirements of the modern economy and modern society. The need to discuss and resolve these issues is associated with finding a strategy to improve the quality of education that meets the needs of the modern labor market. The article aimed to study the possibilities of project training in the implementation of a personality-oriented approach as a modern educational paradigm. The study is based on an analysis of the approaches of domestic and foreign scientists to issues of personality-oriented education and project training. Results: in a personality-oriented learning paradigm, the goal of a university is not only to transfer knowledge but to create an environment and experience that help students find and construct knowledge, create communities of students who make discoveries and solve theoretical and practical tasks.
\end{abstract}

Keywords - personality-oriented education, project-based learning, self-actualization, problem-based learning, practiceoriented learning.

\section{INTRODUCTION}

The implementation of personality-oriented education is particularly relevant in the context of the development of modern education. The traditional system focused on the differentiation of knowledge and authoritarianism. The modern education system is based on principles such as the integration of knowledge, humanism, dialogism, and culture of dignity. The modern educational paradigm considers a person as a unique individual with spiritual, creative potential. The purpose of modern education is a person striving for selfactualization. A person in order to realize his abilities in a dynamically developing world needs an education system, which as a result, will allow a person to open to the perception of new experiences, lifelong learning.

The teacher should teach a person to learn, acquire knowledge, analyze it, and be able to put it into practice. Often the theory in education is divorced from practice, and the problem arises of applying existing knowledge, skills, and competencies to professional activities. Modern employers often note the isolation of graduate knowledge from production practice and the dominance of theory over practice. Studying at a university is the most crucial stage of comprehensive human education.

One of the most critical tasks of modern education is the creation of vectors of student-centered learning. In recent years, the process of development and modernization of higher education in Russia has been associated with the ideas of project education. This trend is especially brightly developing in technical universities, students, and graduates of which provide a significant degree of scientific and technical and informational progress of the country. The leading strategic solution to this issue is the introduction of design training in universities.

One of the current trends in the development of the Russian education system is the introduction of project-based learning at universities. The substantial aspects of project training and the tendency to introduce its elements into the education system arose in Russian educational practice and theory. The widespread introduction of project-based education at Russian universities began in 2014. There was no universal solution to the problems posed in 2017, and each university was forced to cope independently with the difficulties of introducing project education.

The relevance of the study is because, at the current stage of the implementation of project training in Russian 
development $[6 ; 8 ; 14]$. One of the essential personality traits is the ability to learn, moreover, to learn throughout life. One of the most effective educational methods is project training, which based on problem-oriented teaching [2;11].

The concept of "problem-oriented learning" is used for denoting both pedagogical theory and educational practice, teaching models $[24$, p. 65]. This approach is implemented in the process of teaching different disciplines in different national contexts. Project training is implemented in the preparation of specialists in the field of business, the media, natural, technical fields, education, in the field of information technology and sustainable development and other areas [5; 26].

Project training is an important component of a personality-oriented approach. The student's role changes from learning through the perception of information to learning through practice [27, p. 255]. The methodological basis of project training consists of the following principles:

- training in practice $[3 ; 6 ; 18]$;

- solving real-world problems $[2 ; 5 ; 23]$;

- interdisciplinarity $[21 ; 28]$;

- dialogic nature of the communicative process $[10 ; 26$; $28]$ introduction of project training in universities should be to increase the competitiveness of graduates in the labor market. The development of the methodology and an attempt to discuss the problems that have arisen and found solutions to them by the forces of representatives of different universities will help to become more widespread and quality in project training at universities of the Russian Federation.

The purpose of the article is to study the project training possibilities in the implementation of a personality-oriented approach as a modern educational paradigm.

\section{MATERIALS AND METHODS}

Orientation on the students' personality in the education process is present in the Russian pedagogical theories of K.D. Ushinsky, P.F. Kapterev [1]. Today, the role of the personality factor in learning is becoming the basis of a personalityoriented education paradigm, in which the idea of a deliberate transformation by a person of the world and himself is crucial. The basis of a personality-oriented education is humanistic principles, the idea of a person's natural predisposition to creativity, spirituality, and morality.

The development of personality-oriented education is due to the development of the humanistic trend in world pedagogy. Significant for this study is the theoretical ideas of foreign humanistic thought, the pedagogical practice of foreign and Russian pedagogy $[1 ; 6 ; 14]$. The introduction of projectoriented training is one of the directions for the development of education around the world $[7 ; 25 ; 26]$.

Changes in the educational system and the development of a personality-oriented system are due to the requirements of the modern economy and modern society. The introduction of project training aimed at developing personal skills and competencies of students are contributing to their professional
- cooperation and group work [26; 27];

- focus on obtaining a specific result, the final product $[17$; $19 ; 22]$

- problematic nature of training $[16 ; 22 ; 25]$

- systematic and integrity of training $[13 ; 22 ; 25]$;

- the role of the socio-cultural context in the implementation of educational programs $[4 ; 20 ; 26]$ and other principles.

\section{RESEARCH RESULTS AND DISCUSSION}

According to the philosopher, teacher, and methodologist of project training, J. Dewey, project training is learning through action, through solving practical complex team problems that are interesting for students. The term project itself (lat. "Projection" - throwing ahead) involves the creation of the design of a possible object, state, action.

Students focus on changing reality. From chaos and disorder at the starting point of the design, they are invited to come to an ordered and thoroughly analyzed result, planned, and created together.

A project is not only an ideal plan, a draft, an outline of the result of an activity. Project management specialists identify the following project attributes.

Firstly, the design task should be unique, ambiguous, causing questions, sometimes disputes. If it is clear to all participants in a training project what to do in advance, then the training potential of such a project should not be highly rated. This situation can be compared to how if tenth graders are forced to solve problems from elementary school. The task 
should be involved, requiring a creative solution for many people. K. Gray and E. Larson [3] wrote that a project is never the same. It always contains some unique elements. The important thing is not whether they will take place, but how unique they are. This true even for basic construction projects. Implementation of construction projects well-known and welldeveloped methods and techniques are used, require some degree of "fitting," which makes them unique" [3, p. 14].

Secondly, the design task should be a team. A project is always the work of several people, each of whom has a specific, predetermined role on the project. Ideally, the project team should not have ballast. Each member of the working group in the training project should have its role.

Thirdly, any project has a bright start and end time. There are educational projects with a length of an academic hour, and there are projects for six months. All members of the project team should know from the very beginning how much time they have at their disposal. The factor of the deadline and intermediate deadlines is one of the essential features of the project.

Fourthly, a project is always infrastructure. A place should be equipped (a table or a room) in which the participants of the project working group will gather and work. J. Dewey in training suggests starting from the activity of students, their desire for knowledge, which are expressed in initiative, interest, participation, creativity. The philosopher emphasizes that abstract tasks do not cause students any interest. Dewey believes that the beginning of thinking is in any difficulty, embarrassment, or doubt. Thinking is not a case of spontaneous combustion and does not arise based on "general principles." Dewey emphasizes that there is something specific that produces and causes a person's thinking to become active. It is not true that the general suggestion to the child (or adult) is to think independently of the existence of difficulty in his personal experience, which confuses him and unbalances him. Dewey writes that this advice is as fruitless as the advice to raise yourself by the ears from the boots $[6, \mathrm{p}$. fifteen]. A person is characterized by a desire to gain experience. J. Dewey understands experience as the ability to foresee the results of activities in the intellectual, moral, and social spheres.

Dewey emphasized that the student is not just a vessel that needs to be "filled" with knowledge. Knowledge, without their relevance in the personal, social contexts, remains a dead weight and is most likely forgotten. Therefore, the basis of the methodology of project training is not a subject-object, but a subject-subject scheme, which involves a direct appeal to the interests of the student. In the subject-subject scheme, the teacher and student are equal partners in the process of creative creation of the project at all stages.

The nature of communication and interaction changes from monologic when the teacher speaks, and the students listen to the dialogue. The teacher and the students discuss the purpose and nature of the necessary changes. Further, the participants, according to a certain technique, carry out a creative project, jointly carrying out work [7]. During the work, their knowledge and skills deepen and expand. P. Freire recognizes the importance of the dialogical method of teacher-student interaction in the process of cognition, problem statement, and project implementation. P. Freyrethinks that through dialogue, the teacher of students and student teachers ceases to exist and a new term appears teacher-student with student teachers. The teacher is no longer the one who teaches, but the one who learns himself in dialogue with the students, who, in turn, being taught also teaches. They become jointly responsible for the process in which everyone grows $[15$, p. 30].

The theoretical justification of the project is not limited to the deductive-inductive traditional methodology. The project justification includes a heuristic-probabilistic methodology that involves the activation of creative processes: design analysis, morphological analysis, methods of focal objects, information redundancy and insufficiency, Delphi method, and other methods.

Project training cannot be fully implemented within one teaching theory, or within one method, it involves a complex nature, it necessarily contains an innovative component.

As N.V. notes Matyash: "The goal of project training is to develop students as subjects of creative activity, to prepare them for successful and harmonious functioning in an informationally and technologically saturated world" $[10, \mathrm{p}$. 45].

The project teaching methodology includes traditional, active, and creative methods. Project-based training represents groundwork in the field of pedagogy and the actual application of project management methods. Training is carried out in several stages:

The first stage of the project activity is the research (preparatory) stage, which determines the scope of reality, in which there are significant problems that need to be resolved. Analytical understanding of a problem situation requires its discussion, as well as the application of such methods as demonstrating samples of already completed projects, brainstorming, drawing up mental maps, the method of focal objects, and morphological analysis.

To organize a discussion, the teacher needs to think over a problematic situation that may interest students, the organization of a discussion (rules, the correctness of value judgments, constructive criticism), problematic issues that stimulate the promotion of exciting projects. It is necessary to take into account the specifics of working with children: as a rule, it is not very easy for them to independently choose the topic of the project.

In the case of project management for adults, this does not seem to be very difficult. As a rule, a team of adults will easily choose the actual project for themselves. With children, this initial stage is hardly one of the most important. The problem to be solved should be relevant, attract attention, and not be artificial. When organizing the preliminary stage, it makes sense to maintain a balance.

On the one hand, the teacher must proceed from the students' request. Nevertheless, on the other hand, the teacher must make sure that the result meets the definition and characteristics of the project and is quite complicated for the student team. Too simple a project will not be exciting. As a 
Events of the "School of Mentors" are organized in many Russian cities, such as Chelyabinsk, Tomsk, Yekaterinburg, Novosibirsk, and other cities. Specialists in project activities were able to expand their professional competencies by participating in lectures, workshops, contests, webinars, and forums. This achievement has become possible, among other things, because the School of Mentors implements two training formats for organizers and mentors of project activities: full-time and online education.

As one of the practical goals, the "School of Mentors" declares the need to increase the number of projects that could develop into technological startups. For this, it is necessary not only to prepare specialists but to integrate them into educational institutions. Classroom hours at the university are still needed. Exciting lectures and discussions at the seminars form students' interest in particular issues and the desire for a deeper understanding of them in the framework of subsequent projects. M. Gell-Man suggested moving away from the sage on the stage to a guide standing aside [9, p. 9].

The curators, mentors of the project activities, are called upon to become such peculiar guides. It is the curators who provide "the possibility of the project to exist." The curators have the necessary knowledge in a specific professional field, so the curators coordinate the work of the whole team. The curators encourage the participants to complete the tasks themselves and bring the project to completion. The curator does not interfere with the content of the work. The task of the mentor (curator) is to accompany, support the team and the project. That is, the curator organizes communication inside and outside the project and directs students to formulate problems, goals, and objectives for its solution. With this approach, the student is able not only to reproduce existing knowledge and practices but to form new ones, often competitive at different levels.

There are two types of mentoring - direct and indirect mentoring. Direct mentoring is direct contact with the student, with the group in formal and informal settings. Indirect mentoring is formal mentoring through advice and recommendations within working hours and minimizing all informal contacts.

In the "School of Mentors" preference is given to the first form, since when working in an "open situation", the cocreativity of the mentor and students allows most effectively solving the task

The relevance and popularity of the "School of Mentors" events led to the launch and development of new projects, such as the "Academy of Mentors," "Exchange of Mentors." Their goal is to increase the number of specialists in project activities and their certification. The implementation of these projects related to the inclusion of project activities in the educational environment involves the growth and development of a community of mentors, their professionalism. The consequence of this process is the transformation of the educational process itself, increasing the effectiveness of the education system. Admission to the "School of Mentors" takes place on a competitive basis. The number of applications significantly exceeds the throughput of this organization. This circumstance indicates a high demand 
from the educational environment. This circumstance also indicates that such a system has become an essential tool for broadcasting and replicating various types and practices of mentoring.

\section{CONCLUSION}

The introduction and development of the idea of project training required the development and modernization of available resources, equipment, increasing and expanding the functions of a teacher, changing the teaching and methodological complex, and analyzing state educational standards. Part of these changes is aimed at reforming, improving individual elements, and part of improving the entire system as a whole. During the implementation of the idea of project education in the universities mentioned above, all the studied disciplines are considered in the context of the student's professional competence, and "professionalization of the disciplines" takes place. When introducing a systematic approach to training, the convergence of educational and professional competencies occurs, which ensures the most effective learning outcomes. Initially, the student must form general ideas about the project and his future professional activities. After meeting and understanding the ultimate goal, he can begin to master the first basic, and subsequently, specialized professional knowledge and skills. In this case, it is necessary to develop the motivational side, directing the student to the realization of a conscious set goal. In the course of training, it is necessary not only to give specific professional competencies to students but also to teach them how to put them into practice to teach them how to analyze their actions and their consequences.

For a complete transition to project training, it is necessary to develop a regulatory and methodological framework (new work plans, programs, study books), a financial model of the entire educational process in a new format, and also allocate time (classroom and extracurricular) for the implementation of projects (monodisciplinary in the first courses and interdisciplinary for seniors) and equip a particular audience a kind of resource center for a new model of education.

The role of managers in educational programs and projects in the new model is growing. They now require more mobility, activity, and immersion in the study area. They should formulate topics, names of projects that will not only interest students but also allow combining theoretical and practical competencies. Note that the theme of the projects should be relevant among potential employers, regularly updated. Therefore, in the transition to project training, it is necessary to survey potential employers to formulate those competencies, skills, ideas that are relevant in a particular area at the moment. This circumstance leads to the need for cooperation between teachers of humanitarian disciplines and workers in the field of information technology.

Another essential project manager task is to assess the contribution of each team member to the development and implementation of the project. At the end of the semester, it is supposed to carry out offsets on projects. The difficulty connects with the fact that according to the teamwork results, the leader must evaluate the work and participation of each individually.

One of the essential advantages of project education is an orientation to practice. Students learn and acquire the necessary competencies in the framework of training and production practices. The training complex is compiled, taking into account the possibilities of the practical application of skills and competencies. For example, in the course of the thesis, students solve specific production problems and tasks.

In a personality-oriented learning paradigm, the goal of a university is to create an environment and experience that helps students discover and construct knowledge for themselves. The project as a learning tool allows creating communities of students who make discoveries and solve theoretical and practical problems. The idea to learn how to put theoretical competencies into practice before employment is very relevant. The introduction of project-based training raises the university's rating for both students and employers hiring graduates. Moreover, the employer, accepting a graduate who has completed project training, is more confident in his professional competencies, knows that he can be immediately entrusted with real production tasks. The graduate himself is more confident in his competencies since his theory of education is not divorced from professional activity.

\section{References}

[1] A.V. Babayan, "Fundamental theories of moral education Ushinsky KD, Kaptereva PF, Hessena SI,” Basic research, 2009, № 3-S, pp. 77-79.

[2] O.A. Brel, "Technologies of problem-oriented education in professional tourism education,” Higher education today, 2015, № 10, pp. 22-26.

[3] K. Gray, W. Larson, Project Management. M.: "Delo and Service," 2007.

[4] M.O. Guzikova, "The linguistic environment of world universities in the context of the internationalization of higher education." Perspektivy nauki i obrazovania - Perspectives of Science and Education, 2019, № 42 (6), pp. 158-171.

[5] S. I., Dvoretskiy, N.P. Puchkov, "Preparation for project activities as a means of ensuring the professional competence of a graduate of a technical university," Vestnik TSTU 2002, vol. 8(2), pp. 351-364.

[6] J. Dewey, Psychology and pedagogy of thinking. M.: "Labyrinth," 1999.

[7] M.A. Dyachkova, O.N. Tomyuk, "Interactive forms of improving the professional competence of additional education teachers," Discussion, 2017, № 11(85), pp. 98-102.

[8] A.G. Egorova, "The project method as a technology of a personalityoriented approach," Lingua mobilis, 2013, No. 6 (45), pp. 83-87.

[9] E.F. Crowley, S. Ostlund, D.R. Broder, K. Edstrom, Rethinking engineering education. CDIO approach. M.: HSE Publishing House, 2007.

[10] N.V. Matyash Innovative pedagogical technologies. Project Training: Textbook. allowance for students. Higher education institutions prof. Education. M.: “Academy," 2011.

[11] M.G. Minin, N.Yu. Vyuzhanina, "The implementation of problemoriented and design-organizational training at leading universities in the world," News of Altai State University, 2013, No. 2-1 (78), pp. 29-32.

[12] O.N. Tomyuk, I.A. Filonenko "Project activity as a condition for the development of the personality of schoolchildren," Modern problems of education Collection of scientific articles, Ekaterinburg, 2014, pp. 30-33.

[13] O. N. Tomyuk, M. A. Dyachkova, N. B. Kirillova, A. Yu. Dudchik, "Digitalization of the educational environment as a factor of personal and professional self-determination of students," Perspektivy nauki i 
[22] M. Hanus, L. Havelkova, “Teachers' Concepts of Map-Skill Development," Journal of geography, 2019, vol. 118 (3), pp. 101-116. pp. $422-434$

[14] Z.M. Urusova, "Personality-oriented approach as a strategy of the modern educational process," Bulletin of Maykop State Technological University, 2013, № 2, pp. 132-137.

[15] P. Freire, Pedagogy of the oppressed. M.: "Alphabet-Atticus," 2018.

[16] M. Beek ter, M.-C. Opdenakker, M.I. Deunk, J.-W. Strijbos, "Teaching reading strategies in history lessons: A micro-level analysis of professional development training and its practical challenges," Studies in Educational Evaluation, 2019, issue 63, pp. 26-40.

[17] S. Bell "Project-Based Learning for the 21st Century: Skills for the Future," The Clearing House: A Journal of Educational Strategies, Issues and Ideas, 2010 , vol. 83 (2), pp. 39-43.

[18] M. Botha, "A project-based learning approach as a method of teaching entrepreneurship to a large group of undergraduate students in South Africa," Education as Change, 2010, vol. 14(2), pp. 213-232.

[19] G.L. Danford, "Project-based Learning and International Business Education," Journal of Teaching in International Business, 2006, vol.18(1), pp.7-25.

[20] H. Jenkins, Clinton K., Purushotma R., Robison A. J., Weigel M. Confronting the Challenges of Participatory Culture: Media Education for the 21st Century. EE. UU.: MacArthur Foundation, 2009, 68 p.

[21] R. Hanney, M. Savin-Baden, "The problem of projects: understanding the theoretical underpinnings of project-led PBL," London Review of Education, 2013, vol. 11 (1), pp. 7-19.
[23] B.J. Kim, D.M. Rousseau, M.Tomprou, "Training and Diffusion of Change: The Impact of Training and Proactivity on Change-Related Advice Giving," Journal of Applied Behavioral Science, 2019, vol. 55(4), pp. 453-476.

[24] A. Kolmos, "Facilitating Change to a Problem-based Model," The 74.

[25] A. Kolmos, "Problem-Based and Project-Based Learning," University Science and Mathematics Education in Transition, 2009, pp. 261-280.

[26] M. Lehmann, P. Christensen, X. Du, M. Thrane, "Problem-oriented and sustainable development in engineering education," European Journal of Engineering Education, 2008, vol. 33 (3), pp. 283-295.

[27] M. Stauffacher, A. Walter, et al., "Learning to research environmental problems from a functional socio-cultural constructivism perspective: the transdisciplinary case study approach," International Journal of Sustainability in Higher Education, 2006, vol. 7(3), pp. 252-275.

[28] N.P. Tsepeleva, "Dialogue as a form of social construction in everyday life," European Journal of Science and Theology, 2018, vol. 14(4), pp. 131-141. International Journal for Academic Development, 2002, № 7(1), pp. 63project-based learning (POPBL) as an innovative learning strategy for 